\title{
El verdadero yo en los inéditos o los átomos de la estética proustiana
}

Proust, M. (2021). El remitente misterioso y otros relatos inéditos (173 pp.). Buenos Aires: Lumen.

\section{MARCEL PROUST}

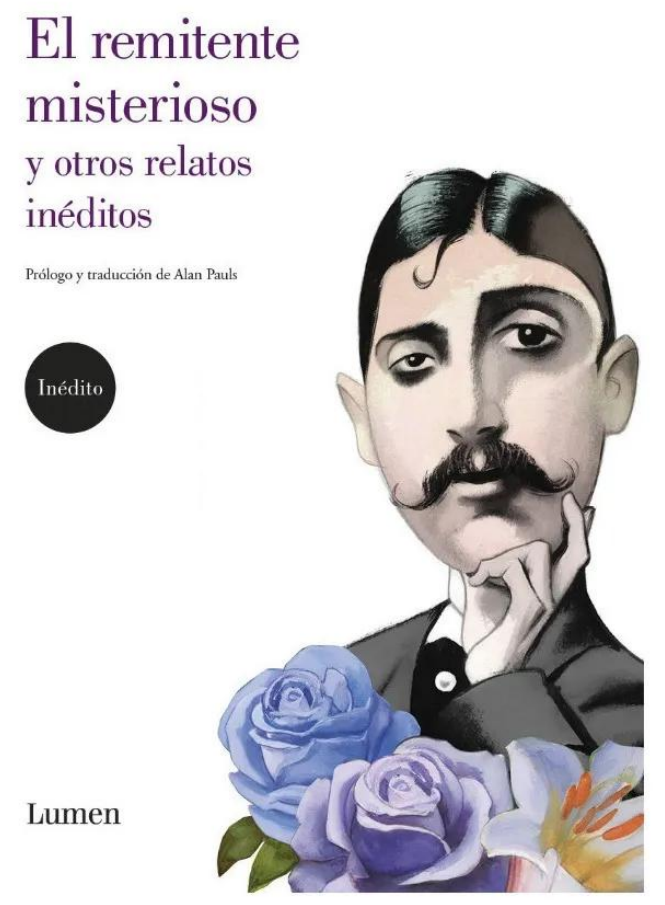

"He llegado a un momento, o si se quiere, me encuentro en tales circunstancias, que puede temerse que las cosas que más quería decir... ya no pueda decirlas de una vez." (Proust en

Contra Sainte- Beuve)

\footnotetext{
* Licenciada en Letras Modernas, profesora adscripta en Literaturas Europeas Comparadas y ayudante-alumna en Estética y Crítica Literaria Modernas, Facultad de Filosofía y Humanidades, Universidad Nacional de Córdoba, Córdoba, Argentina. videlamartinezjulieta@ gmail.com. Recibido 13/03/2021. Aceptado 02/05/2021.
} 
[Je suis arrivé à un moment, ou, si l'on veut, je me trouve dans telles circonstances où l'on peut craindre que les choses qu'on désirait le plus dire... on ne puisse plus tout d'un coup les dire.] (Proust en Contre Sainte-Beuve)

Hoy tenemos, después de más de un siglo desde la publicación de Du côté de chez Swann, el primer tomo de À la recherche du temps perdu, la publicación de nueve textos (relatos y fragmentos íntimos), que hasta ahora habían permanecido inéditos - excluyendo "Recuerdo de un capitán"- Lo que se cuestiona principalmente la crítica con esta novedosa antología, que recién ahora resucita de entre tantos borradores proustianos, es por qué su creador se negó, no solo a la publicación de ellos, sino también a haberlos comentado con nadie. En la introducción a este conjunto de escritos íntimos, Luc Fraisse, profesor de la Universidad de Estrasburgo e investigador del proceso de creación literaria de Marcel Proust, sostiene que el tema que emparenta a estos textos - y en consecuencia, uno de los motivos por los cuales han permanecido en la oscuridad - es la homosexualidad. Sin embargo, Fraisse destaca que esta respuesta no es contundente ni suficiente, aunque él mismo reafirme la idea de la homosexualidad a lo largo de toda la introducción y las notas que acompañan a cada texto, porque también manifiesta que no es la "forma de resolver de manera definitiva todos los enigmas" (Fraisse, en Proust, 2021, p. 22) que plantea la aparición de estos textos. Claramente, lo que nos revelan es algo más que el tema de la homosexualidad que los vincula a unos con otros, pero dicho tema es el primer paso para conocer y entender el otro yo de Proust que, en soledad y aislamiento, lejos de todo lo que lo rodea, incluso de sus costumbres, le permite manifestarse como obra artística en su totalidad, porque estos inéditos son el resultado de las formas extraídas de lo "sobrenatural" (Proust, 2011).

Si Proust se nos revela hoy, tan lejos de su tiempo, en ese Proust avant Proust que investigó Bernard de Fallois, es porque se hizo esperar para que los "hombres de mundo" pudiéramos ver los átomos de su formación en proceso y entender que, tal como lo piensan Fraisse y de Fallois, la Recherche no se escribió de una vez y de golpe. Claros ejemplos son Les plaisirs et les jours, Jean Santeuil y Contre Sainte-Beuve.

Esta compilación reúne una serie de textos de Marcel Proust transcritos por Luc Fraisse de los archivos de Bernard de Fallois y son traducidos aquí por Alan Pauls. Todos, excepto el ya mencionado más arriba, permanecieron inéditos hasta el año 2019, pero según las investigaciones de de Fallois, datan de la misma época de Les plaisirs et les jours: ¿fragmentos y relatos descartados de la primera obra? Según Fraisse, si estos hubiesen sido incluidos, la homosexualidad se habría convertido en el tópico principal del libro, de manera que quedaron bajo la sombra durante un largo tiempo. Esta revelación reciente nos conduce, en primer lugar, a la idea de un Proust que a lo largo de toda su vida experimentó diversas formas literarias (el cuento fantástico, como "El don de las hadas"; el relato de suspense como "Jacques Lefelde" o "El remitente misterioso"; la fábula, como "La conciencia de amarla"; o la novela misma posteriormente) con un mismo material que va de un tiempo perdido en los placeres y las frivolidades a un tiempo recobrado en la recuperación de la infancia y la hipersensibilidad de la enfermedad; y en segundo lugar, a la imagen de un Proust con un gesto plenamente romántico (el romanticismo de la segunda generación francesa) que se retrotrae y escapa de un escribir para el público y de lo social, porque ve emerger en su interior el otro yo, el verdadero yo que se emancipa del yo abrumado del día, de los salones y de la sociedad, de ese yo "enmascarado", como lo entendía Charles Nodier en De quelques phénomènes du sommeil. El verdadero yo se inmiscuye en lo sobrenatural baudeleriano tan opuesto a lo natural pero a la vez a lo social, porque es de ese mundo sobrenatural y antiprosaico del que extrae las formas del arte.

Además, la antología cuenta con una introducción, unas notas que anteceden a cada escrito y un apéndice de Fraisse. La primera desarrolla dos ideas centrales en la literatura temprana 
de Proust: el tópico de la homosexualidad que vincula a los relatos y la importancia del estudio de estos textos como una experimentación constante hasta la cumbre de la Recherche. Las notas previas a cada relato adelantan la temática que se desarrollará, pero también menciona ciertas influencias, como El cuervo, de Edgar Allan Poe, o recuperaciones de esas temáticas en su monumental obra. El apéndice titulado "A las fuentes de En busca del tiempo perdido" se traslada a elementos fundamentales que se encuentran en los cimientos de la gran novela, como el contacto con el sociólogo Gabriel Tarde; el conocimiento y el aporte que produjo La volonté de la métamorphose de Joseph Baruzi vinculada con la teoría sobre la voluntad, de Shopenhauer; la reescritura incesante y experimental del inicio de DCS en la que oscila entre la vigilia y el sueño, rastreada en todas sus versiones en los textos tempranos que muestran cómo Proust trabaja toda su vida con la misma idea estética; la homosexualidad, el amor y el narrador. Hacia el final, el libro tiene como anexo un cuaderno iconográfico en el que se pueden apreciar imágenes de los manuscritos y los borradores de Proust, tarjetas postales y un mapa de Balbec, dibujado por el escritor.

Como lo hemos mencionado anteriormente, la traducción es realizada por Alan Pauls, quien, además, escribió el prólogo del libro en donde deja claro que la importancia de la lectura de estos textos tempranos supera el tópico de la homosexualidad. Pauls se pregunta si acaso ya no lo incluía todo la gran novela de Proust a tal punto de hacer desaparecer aquello otro que pueda o no haber escrito, incluso Contre Sainte-Beuve, Jean Santeuil, L'indifférent o Les plaisirs et les jours. Sin embargo, cuando el lector aborda alguno de estos inéditos, ocurre lo mismo que cuando retoma la Recherche: "algo — un ritmo, una respiración - se reanuda" (Pauls en Proust, 2021, p. 10). En este sentido, creemos que la obra de Proust despierta en el lector un deseo imparable de seguir buscando una escritura rítmica. La etapa temprana del escritor nos revela los átomos, las mónadas en transformación de la estética proustiana. En "Pauline de S.", el relato que da inicio al compendio, contemplamos cómo la enfermedad - el cáncer - que aqueja a la amiga del narrador se traslada a este último. Pauline solo se ve enfermiza física, externamente, mientras sigue llevando una vida social y practicando la conversación en distintos eventos, pero el narrador, una noche en que la decide ir a visitar al día siguiente a su amiga, empieza a sentir el malestar de la enfermedad en su interior, lo que le hace percibir los placeres, las diversiones y los trabajos como algo totalmente lejano. El narrador se enferma internamente por un lapso de tiempo, reflexiona sobre la cercanía de la muerte y se acrecientan las meditaciones profundas sobre las artes que nacen del centro de su ser. Este breve cuento se emparenta con "La muerte de Baldassare Silvande", de Les plaisirs et les jours, en el que el enfermo aquí ya no es ni el narrador ni un amigo de este, sino el tío de Alexis, Baldassare. Este relato, a diferencia del inédito, está narrado en tercera persona y coloca una mayor distancia en relación con los acontecimientos. El narrador oscila entre las vidas de los personajes y antes de concentrarse en el decurso de la muerte de Baldassare, se sitúa en el olvido y la naturalización de la enfermedad que siente Alexis hacia su tío, al punto de no sentir conmoción alguna por el moribundo. Una noche, tal como le ocurre al narrador de "Pauline de S.", porque la noche es el momento en el que se despierta la hipersensibilidad, creyó identificarse como un malvado que no se apiada por su tío enfermo, pero rápidamente volvió a pensar en su vida colmada de placeres. Vemos en este punto dos mónadas, dos escenas distintas del átomo de la enfermedad. Posteriormente, el narrador se ubicará en las sensaciones y las reflexiones del enfermo, dibujando la proximidad de la muerte y el desarrollo avanzado de los síntomas de la parálisis general como el despertar o la existencia enérgica del yo verdadero que se une con la contemplación estética, en oposición a los momentos de bienestar corporal como la muerte de ese yo íntimo. Es claro el esfuerzo y el trabajo escritural que realiza Proust en esta época sobre una idea de la autonomización del arte a través de la enfermedad buscando el yo proustiano o el narrador que se separará de la figura del escritor. 
"Recuerdo de un capitán", el único cuento que sí había sido publicado por Bernard de Fallois el 22 de noviembre de 1952 en Le Figaro, materializa tres elementos centrales de la estética proustiana: la construcción del yo, la meditación de la memoria y la homosexualidad. Pone originalmente en escena la narración de una emoción homosexual inconsciente a partir de un recuerdo de una primera persona. El intenso trabajo de este material se relaciona con "El remitente misterioso", el cual traslada la homosexualidad al género femenino, y, tal como lo anuncian de Fallois y Fraisse, adelanta algunas escenas de Sodoma y Gomorra. Al mismo tiempo, este cuento es otro mundo posible, otra mónada de la cápsula narrada en "Cuadros de género del recuerdo", de Les plaisirs et les jours. También se podría pensar que este pequeño fragmento podría ser un proemio a la historia contada por el capitán. En efecto, la narración de este texto toma distancia y anuncia de manera generalizada el recuerdo de sus jóvenes compañeros del servicio militar, evocaciones cotidianas que se caracterizan por un derrame estético de belleza, melancolía y poesía.

Tenemos ciertos recuerdos que son como la pintura holandesa de nuestra memoria, cuadros de género en que los personajes suelen ser de condición mediocre, tomados en un momento muy sencillo de su existencia, sin acontecimientos solemnes, a veces sin ningún acontecimiento, en un escenario nada extraordinario y sin grandeza. La naturalidad de los caracteres y la inocencia de la escena constituyen su atractivo, la lejanía pone entre ella y nosotros una luz suave que la baña de belleza... pequeños cuadros llenos de verdad venturosa y de encanto sobre los cuales ha derramado el tiempo su tristeza dulce y su poesía. (Proust, 2018b, pp. 177-178).

[Nous avons certains qui sont comme la peinture hollandaise de notre mémoire, tableaux de genre où les personnages sont souvent de condition médiocre, pris à un moment bien simple de leur existence, sans événements solennels, parfois sans événements du tout, dans un cadre nullement extraordinaire et sans grandeur. Le naturel des caractères et l'innocence de la scène en font l'agrément, l'éloignement met entre elle et nous une lumière douce qui la baigne de beauté... petits tableaux pleins de vérité heureuse et de charme sur lesquels le temps a répandu sa tristesse douce et sa poésie.] (Proust, 1896, pp. 213-214).

Esos cuadros de juventud que, gracias al pasar del tiempo, adoptan rasgos poéticos son individualizados en "Recuerdo de un capitán", en el que el narrador se retrotrae al encuentro con un soldado. El cuadro que le brinda la memoria hace aparecer en ese encuentro, de trasfondo, a un brigadier de guardia al que recuerda eróticamente, haciendo resaltar en los detalles la suavidad de sus ojos y de su boca. Más allá de la homosexualidad inconsciente que el narrador se cuestiona sin explicitar, es interesante el diseño del recuerdo cargado de alegría en el pasado que todavía vive tan dentro de sí, pero al mismo tiempo tan fuera de sí, de modo que ese cuadro, que se ilumina a sí mismo, que tiene su propia belleza, que se basta a sí mismo, es la idea de la autonomización del arte en la que insistirá en todos sus cuadernos y borradores. 
...El recuerdo pintado sin duda con esa frescura deliciosa con que lo haría la luz encantadora de la mañana o de la tarde. Allí está cada pequeño detalle, muy iluminado, y me parece hermoso. Lo veo como desde una colina. Es un pequeño mundo que se basta a sí mismo, que existe fuera de mí, que tiene su belleza suave, en esa luz clara tan inesperada. (Proust, 2021, p. 81).

En esta narración de la historia particular se marca el tiempo del pasado y el del presente. El pasado muestra alegre al corazón, en tanto que el presente lo refleja triste y enfermo. Es este estado febril el que hace posible al pasado con su alegría en el presente, al menos por un instante, en la contemplación detenida de los detalles del cuadro que son casi paralizados. "Relato de un capitán" funciona tal como un haiku: es una cápsula que encierra y detiene un instante de la vida cotidiana del capitán cuando en el pasado era teniente, demora las miradas entre los hombres militares y los deseos que suscitan en ellos.

"El don de las hadas", fragmentado en dos partes, adelanta dos cápsulas que desarrollará más adelante Du côté de chez Swann: la incomprensión de la hipersensibilidad por parte de la gente, que, sin embargo, es un don, y el deseo del objeto, que cuando no se tiene, se anhela y se embellece a través del recuerdo, y cuando se tiene, se desluce y se corrompe porque la visión del objeto real no guarda armonía con la imagen de ese objeto del recuerdo. El hada que le regala el don de la hipersensibilidad al niño le manifiesta que es un obsequio que no puede devolver, que le traerá mucho sufrimiento y tristeza porque en lugar de ser comprendido, será rechazado, burlado y menospreciado. Es el mismo hombre que más tarde en $D u$ côté de chez Swann, en el recuerdo de su niñez, evoca la primera vez que su madre reconoce esa hipersensibilidad como un mal involuntario del que él no es responsable:

«Pero, señora, ¿qué le ocurre al señorito, que llora así?», le respondió: «Pero, ¡si ni siquiera él lo sabe, Françoise! Está nervioso. Prepáreme a escape la cama grande y suba a acostarse». Así, por primera vez no consideraban ya mi tristeza una falta digna de castigo, sino un mal involuntario que acababan de reconocer oficialmente, como un estado nervioso del que yo no era responsable; sentía el alivio de no tener ya que mezclar los escrúpulos con la amargura de mis lágrimas, podía llorar sin pecar. (Proust, 2010, I, p. 45).

[«Mais Madame, qu'a donc Monsieur à pleurer ainsi?» maman lui répondit: «Mais il ne sait pas lui-même, Françoise, il est énervé; préparez-moi vite le grand lit et montez vous coucher. » Ainsi, pour la première fois, ma tristesse n'était plus considérée comme une faute punissable mais comme un mal involontaire qu'on venait de reconnaître officiellement, comme un état nerveux dont je n'étais pas responsable; j'avais le soulagement de n'avoir plus à mêler de scrupules à l'amertume de mes lames, je pouvais pleurer sans péché.] (Proust, 1987-1989, I, p. 37).

La otra mónada que encontramos en este relato fantástico y que será desplegada en la novela tiene que ver con el deseo, el primer deseo del objeto representado en Gilberte, sin mencionarla aún. El narrador dibujará dos imágenes de esta niña que le llegarán a parecer dos personas diferentes, sin embargo, la primera representación que se hace de ella tiene rasgos más ásperos que le permiten sostener a Fraisse la idea de que, en realidad, se trata de un niño: 
...Tú siempre llorarás cuando en los días de lluvia no te lleven a los Campos Elíseos a jugar con una niña a la que amarás y que te pagará, y en los días de sol, cuando os veáis, te entristecerá encontrarla menos hermosa que en las horas de la mañana, cuando, solo en tu habitación, esperabas el momento de verla. (Proust, 2021, p. 129).

Pero, en cuanto me encontraba - tras llegar a los Campos Elíseos y poder lo primero confrontar mi amor, para hacerle sufrir las rectificaciones necesarias, con su causa viva, independiente de mí- delante de aquella Gilberte Swann con cuya vista había contado para refrescar las imágenes que mi fatigada memoria ya no lograba encontrar, de aquella Gilberte Swann con la que había jugado el día anterior y a la que acababa de saludar y reconocer gracias a un instinto ciego, como el que, al caminar, nos hace poner un pie delante del otro antes de haber tenido tiempo de pensar, en seguida parecía que ella y la muchacha objeto de mis sueños fueran dos personas diferentes. (Proust, 2018a, I, p. 420).

[Mais quand j'arrivais aux Champs-Élysées —et que d'abord j'allais pouvoir confronter mon amour, pour lui faire subir les rectifications nécessaires, à sa cause vivante, indépendante de moi- dès que j'étais en présence de cette Gilberte Swann sur la vue de laquelle j'avais compté pour rafraîchir les images que ma mémoire fatiguée ne retrouvait plus, de cette Gilberte Swann avec qui j'avais joué hier, et que venait de me faire saluer et reconnaître un instinct aveugle comme celui qui dans la marche nous met un pied devant l'autre avant que nous ayons eu le temps de penser, aussitôt tout se passait comme si elle et la fillette qui était l'objet de mes rêves avaient été deux êtres différents.] (Proust, 1987-1989, I, p. 394).

Hemos desplegado aquí la comparación de solo tres relatos incluidos en esta antología con otros textos de la época temprana y de la primera parte de la Recherche, con el objetivo de poder dar cuenta de la importancia de la lectura y el estudio de esta etapa de Proust, porque es allí en donde se encuentran los átomos del pensamiento de su estética. El estudio comparativo del proceso de su pensamiento, ese yo íntimo que tanto dudó y negó manifestar nos revela hoy las transformaciones y la consolidación de sus ideas sobre el arte.

\section{Referencias}

Proust, M. (1896). Les plaisirs et les jours. Paris: Calmann Lévy.

Proust, M. (1971). Contre Sainte- Beuve. Paris: Gallimard.

Proust, M. (1987-1989). À la recherche du temps perdu. París: Gallimard.

Proust, M. (2011). Contra Sainte-Beuve. Buenos Aires: Losada.

Proust, M. (2018a). En busca del tiempo perdido. Barcelona: Debolsillo.

Proust, M. (2018b). Los placeres y los días. Madrid: Alianza.

Proust, M. (2021). El remitente misterioso y otros relatos inéditos. Buenos Aires: Lumen. 